\section{Análise da configuração dos fragmentos de cobertura vegetal com base na definição de unidades de paisagem na área urbana de Santa Maria (RS)}

Resumo: Objetiva-se analisar a configuração dos fragmentos de cobertura vegetal da paisagem urbana de Santa Maria (RS), com base em uma proposta de definição de unidades de paisagem para a área. Busca-se na interpretação da paisagem urbana a partir da perspectiva geossistêmica, dialogar com as questões que envolvem a ecologia urbana e a conservação da natureza nas cidades. Desta forma, baseado na nomenclatura de Bertrand (1972), considerou-se a área urbana de Santa Maria como um Geossistema urbano, onde foram identificadas seis diferentes Geofácies, diferenciadas segundo a configuração da estrutura horizontal da cobertura vegetal arbórea (classificada de acordo com Jim, 1989) e com os diferentes padrões de urbanização associados à configuração de vegetação. Para tanto, contou-se com a classificação da imagem GeoEye de 21/09/2011 junto ao software SIG Spring. A análise da distribuição horizontal dos fragmentos de vegetação permitiu a definição das porcentagens de cobertura vegetal arbórea, herbácea e arbustiva de cada unidade de paisagem. Associando características de isolamento de fragmentos arbóreos a um padrão de urbanização de maior adensamento de edificações, destaca-se a Geofácie das áreas densamente edificadas, contendo cerca de $68 \%$ de espaços construídos, que representa aproximadamente $20 \%$ da área urbana do município. Dentre as Geofácies que apresentam uma boa configuração da vegetação arbórea, com fragmentos mais conectados e contínuos, que representam uma porcentagem de arborização de cerca de 76\%, destaca-se a Geofácie de morros do rebordo, que ocupa cerca de 12\% do Geossistema urbano. Apesar das estruturas arbóreas cobrirem aproximadamente 33\% da área urbana de Santa Maria, a análise das unidades de paisagem permite observar que a configuração dos fragmentos de cobertura vegetal tem uma distribuição bastante heterogênea, apresentando condições de isolamento em muitas áreas da cidade. Desse modo, o índice aparentemente adequado de cobertura arbórea não garante a integridade das funcionalidades ambientais em toda a área urbana, já que está muito associado aos grandes fragmentos no norte e centro-leste da cidade.

\section{Analysis of the configuration of vegetation cover fragments based on the definition of landscape units in the urban area of Santa Maria (RS)}

\footnotetext{
Abstract: This study aims to analyze the configuration of the vegetation fragments in the urban landscape of Santa Maria (RS), based on a proposed definition of landscape units to the area. Search on the interpretation of the urban landscape from the perspective geosystemic, the methodological support engage dialoguing with knowledge disseminated in discussions involving urban ecology and nature conservation in cities. Thus, based on the nomenclature of Bertrand (1972), considered the urban area of Santa Maria as an Urban Geosystem, which have been identified six different Geofaces, distinguished considering the combination of the horizontal structure covered by tree vegetation (classified according Jim, 1989), with different urban patterns (in densely built-up areas, on the banks of drainage channels, in areas of hills or fields...). To obtain the features configuration covered by vegetation and the interpretation of different types of urbanization patterns, counted with GeoEye image (21/09/2011), classified in Spring GIS software. The analysis of horizontal distribution of vegetation fragments allowed the definition of the percentages of tree, herbaceous and shrubby vegetation cover to each landscape unit. Associating insulation characteristics of the tree fragments and higher density of buildings of urban pattern, stands out "Geoface densely built-up areas", containing about $68 \%$ built spaces, which represents approximately $20 \%$ of the urban area. Among Geofacies presenting a good configuration of vegetation cover, more connected and continuous fragments that represent a percentage of trees of about $76 \%$ of the area, stands out "Geoface the ridge of hills", which occupies about $12 \%$ of Urban Geosystem. Although the percentage of trees in the urban area of Santa Maria is about 33\%, the contextualized analysis by landscape units can observe that the configuration of fragments of vegetation presents isolated conditions in many areas of the city, this percentage being closely associated large fragments to the north and east-central city.
}

Daniel Borini Alves* Adriano Severo Figueiró**

* Mestre em Geografia pela Universidade Federal de Santa Maria (UFSM). Doutorando no curso de Ordenación del Territorio y Medio Ambiente na Universidad de Zaragoza (UNIZAR), Espanha (Bolsista CAPES - Ciência Sem Fronteiras, proc. 9540/13-0).

** Doutor em Geografia pela Universidade Federal do Rio de Janeiro (UFRJ). Professor do Departamento de Geociências da Universidade Federal de Santa Maria (UFSM).

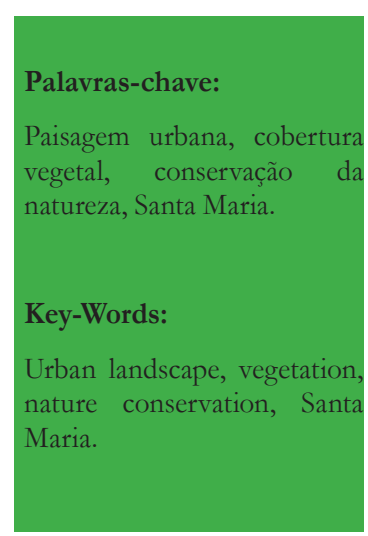

Geografia Ensino \& Pesquisa, vol. 17, n. 3, set./dez. 2013 


\section{Introdução}

Compreender a cidade como um território complexo, onde as questões humanas interagem de uma forma orgânica com os elementos biofísicos, pressupõe compreender não apenas como se ordena e regula o uso e ocupação dos diferentes espaços intraurbanos, mas também a contextualizar a dimensão espacial e temporal dessa ocupação, considerando as interações e os reflexos associados aos processos ecológicos e sociais em múltiplas escalas (TURNER et al, 1989).

Ao analisar-se a dinâmica das paisagens urbanizadas a partir do processo de apropriação e transformação do espaço, observa-se que a impermeabilização dos lotes e a consequente diminuição da cobertura vegetal é um dos fatores mais evidentes e sensíveis nestes ambientes, resultando na diminuição de uma série de funcionalidades ambientais controladas, em grande parte, pela estrutura vegetal (MASCARÓ, 2005).

Essa realidade revela a importância de um planejamento adequado do território, visando a melhoria da qualidade ambiental em áreas urbanas, onde as funcionalidades ambientais sejam valorizadas de forma mais significativa (PICKETT et al, 2001). Para isso, a paisagem urbana, interpretada a partir da configuração estrutural do sistema socioambiental, pode colaborar no sentido de permitir enlaces entre os atributos sociais e naturais e, diferentemente dos recortes administrativos, que são delineados com maior influência de critérios políticos, possibilitar uma análise mais integrada dos mecanismos de controle da dinâmica ecológica, de forma a auxiliar no diagnóstico e planejamento socioambiental da área, desenvolvendo estratégias de conservação e de melhoria da qualidade do sistema (LAURIE, 1979).

Considerando que as unidades de paisagem correspondem a porções do espaço que compartilham uma estrutura (e, por consequência, a dinâmica) ecológica semelhante (FORMAN, 1995), e cujas ligações refletem as trocas de matéria e energia dentro do mesmo nível hierárquico de análise (BEROUTCHACHVILI e MATHIEU, 1977), a sua utilização como recorte espacial de referência para a realização de diagnósticos e proposição de alternativas de manejo, apresenta grandes vantagens sobre outras formas de segmentação da paisagem usualmente utilizadas. Tal é o presente caso, onde se propõe uma análise da fragmentação da vegetação, levando em conta a variabilidade estrutural presente dentro da paisagem urbana do município.

Cabe ressaltar que a existência de altas porcentagens de arborização para determinada unidade de paisagem não implica necessariamente em boas condições de conservação da natureza no sistema socioambiental urbano como um todo, já que para uma maximização dos efeitos positivos da presença da vegetação nas cidades, é necessário que os fragmentos de cobertura vegetal estejam bem distribuídos, revelando a importância da análise da configuração e distribuição espacial de seus fragmentos.

Considerando esse quadro apresentado, tomou-se como área de estudo a paisagem urbana de Santa Maria (RS), uma vez que esta cidade, seguindo a tendência de adensamento populacional acelerado e artificialização do espaço próprio das cidades de porte médio brasileiras, apresentou nas últimas décadas um contexto de perdas do total de cobertura vegetal da ordem de 12,89\% entre 1980 e 2011 . Na zona central da cidade, essas perdas foram ainda mais significativas, chegando a 20,35\% (ALVES, 2012).

Sendo assim, o presente artigo objetiva analisar a configuração dos fragmentos de definição de tipologias de unidades de paisagem para a área. Buscou-se na interpretação da paisagem urbana, a partir da perspectiva geossistêmica (ROUGERIE e BEROUTCHACHVILI, 1991), o suporte metodológico para alcançar os objetivos propostos, dialogando com saberes difundidos nas discussões que envolvem a ecologia urbana e a conservação da natureza nas cidades. 


\section{A paisagem, o geossistema urbano e a cobertura vegetal}

A investigação da paisagem como categoria espacial hierarquizada e sistêmica de análise exige uma boa adequação teórico-metodológica, sendo a abordagem geossistêmica extremamente útil para esta tarefa, já que as unidades de paisagem são interpretadas a partir das interações que estabelecem entre si no processo de transferência de matéria e energia inerente ao metabolismo sociobiofísico que the é próprio.

Monteiro (2000) aborda que a compreensão geossistêmica da paisagem, que pressupõe o entendimento das dimensões espacial e temporal, natural e social, apresenta uma integração das escalas vertical e horizontal, onde a análise geográfica é desenvolvida de forma estruturada e hierárquica. De acordo com o autor, a abordagem geossistêmica objetiva uma visão integradora, que passa por uma etapa de análise das varáveis naturais e antrópicas e uma segunda etapa de integração, onde se fundem os recursos, usos e os problemas, que são configurados na etapa de síntese em unidades homogêneas. Essas etapas conduzem para uma análise interpretativa, onde se avalia a qualidade do meio ambiente, resultando em uma abordagem que contempla a dimensão temporal e espacial, além das inter-relações entre a sociedade e o meio ambiente dentro de uma paisagem histórica concreta.

Diante desta complexa relação dos elementos da paisagem, Bertrand (1972) propôs um sistema taxonômico que permite realizar recortes espaciais considerando a estrutura hierárquica da paisagem e o seu funcionamento em função da escala temporo-espacial selecionada. No presente caso, interessam-nos aquelas unidades consideradas pelo autor (op.cit.) como "unidades inferiores de análise", cujo critério de delimitação resulta diretamente do produto entre o subsistema humano e o sub-sistema biofísico, sendo elas o Geossistema, as Geofácies e os Geótopos (RODRIGUES, 2001; GARCIA-ROMERO e JIMÉNEZ, 2002).

O esquema da Figura 1 sistematiza a integração hierárquica do conjunto de elementos da paisagem, identificando a dependência de uns em relação aos outros. No primeiro nível de integração geoecológica, observam-se os chamados componentes macroestruturais, que correspondem às morfoestruturas submetidas à ação climática. No segundo nível de integração geoecológica observase o produto da interação mesoestrutural, que dispõe de componentes abióticos (o relevo e a água) e componentes bióticos (solos, vegetação e a sociedade). No modelo, o nível de dependência de uns elementos sobre os outros em termos de resultante paisagística, aumenta da esquerda para a direita, fazendo com que a maior parte dos níveis regulatórios e explicativos das estruturas locais estejam situados em escalas superiores, para além do imediatamente visível, o que acaba por definir a necessária multiescalaridade no processo interpretativo da paisagem (FIGUEIRÓ, 2011).

Figura 1 - Integração sistêmica dos elementos na paisagem geográfica.

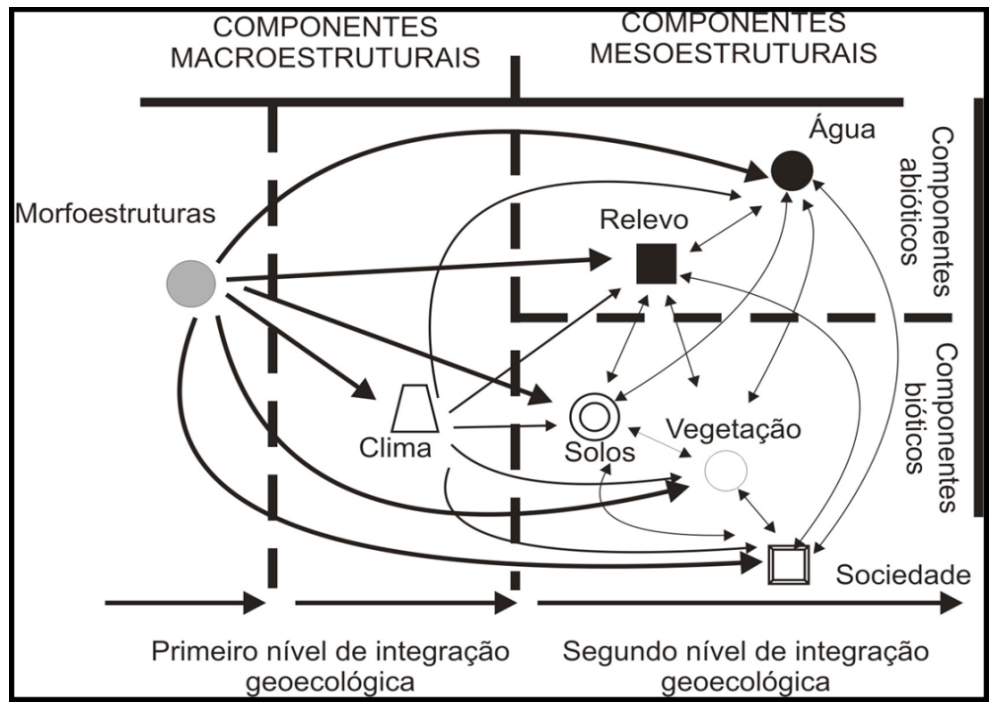

Fonte: Figueiró (2011, p.36). 
${ }^{1}$ Para Rodrigues et al (2010) entende-se por hemerobia às mudanças ocorridas na estrutura e funcionamento da paisagem devido a ação humana direta (antrópica) ou indireta (antropogênica),e que se reflete no grau de estabilidade dos geossistemas.

Geografia Ensino \& Pesquisa, v. 17, n.3, p. 209-228, set./dez. 2013

Análise da configuração dos fragmentos de cobertura vegetal com base na definição de unidades de paisagem na área urbana de Santa Maria (RS)
Destaca-se neste trabalho o papel da vegetação, presente no segundo nível de integração geoecológica, junto aos demais componentes bióticos. Ao depender dos elementos de integração geoecológica situados nas escalas superiores e, por exercer importante papel no nível de integração mesoestrutural, a vegetação contém uma quantidade de informações significativas na compreensão da paisagem local, servindo como importante indicador do grau de qualidade, especialmente dos sistemas urbanos (BERRY e HORTON, 1974), já que, tal como afirmam Sukopp e Werner (1991), nas cidades o clima, o ciclo de nutrientes, o fluxo energético, a estrutura espacial e o inventário biológico diferem substancialmente de seu entorno rural.

Para além da compreensão da interação dos processos envolvidos, Monteiro (2000) afirma que a integração antrópica nos geossistemas deve considerar o seguinte trinômio: a configuração espacial mediante a reflexão sobre a escala de abordagem; configuração temporal, ou duração histórica da ocupação e sua importância histórica no processo de relação no geossistema; a estrutura interna e dinamismo funcional, identificando o grau de intensidade das manifestações antropogênicas.

Assim, a paisagem urbana pode ser descrita como um complexo mosaico de elementos físicos e biológicos que interatuam em uma matriz de infraestrutura e organização social (ALBERTI, 2005), refletindo o grau artificialização impresso pela sociedade que ali predomina, de acordo com os condicionamentos do sítio urbano.

No âmbito da geoecologia, a paisagem urbana pode ser analisada a partir do enfoque histórico-antropogênico, que denotará as regularidades de modificações e transformações estruturais produzidas pelas atividades humanas (RODRIGUES et al, 2010). O conceito de hemerobia ${ }^{1}$ é muito esclarecedor nesse sentido, ao permitir diferenciar o grau de artificialidade ou naturalidade dentro da paisagem urbana.

Em um modelo conceitual que integra os processos humanos e ecológicos para a compreensão do desenvolvimento urbano (Figura 2), Alberti (2005) apresenta a existência de mecanismos de retroalimentação, tais como as mudanças da cobertura da terra, introdução de novas espécies ou emissões de poluentes, que geram determinados efeitos tanto na biodiversidade quanto no ciclo de materiais e nutrientes, os quais, por sua vez, estão relacionados a determinadas variáveis controladoras do processo de ocupação, como a demografia urbana e o planejamento do uso e cobertura da terra. Estes elementos, por conseguinte, estarão associados a determinados padrões de urbanização que vão se expressar em uma forma urbana, uma intensidade de ocupação, um grau de heterogeneidade e conectividade singulares de uso da terra em cada geossistema específico.

Figura 2 - Efeitos dos padrões de urbanização nos processos sociais e ambientais junto à paisagem urbana.

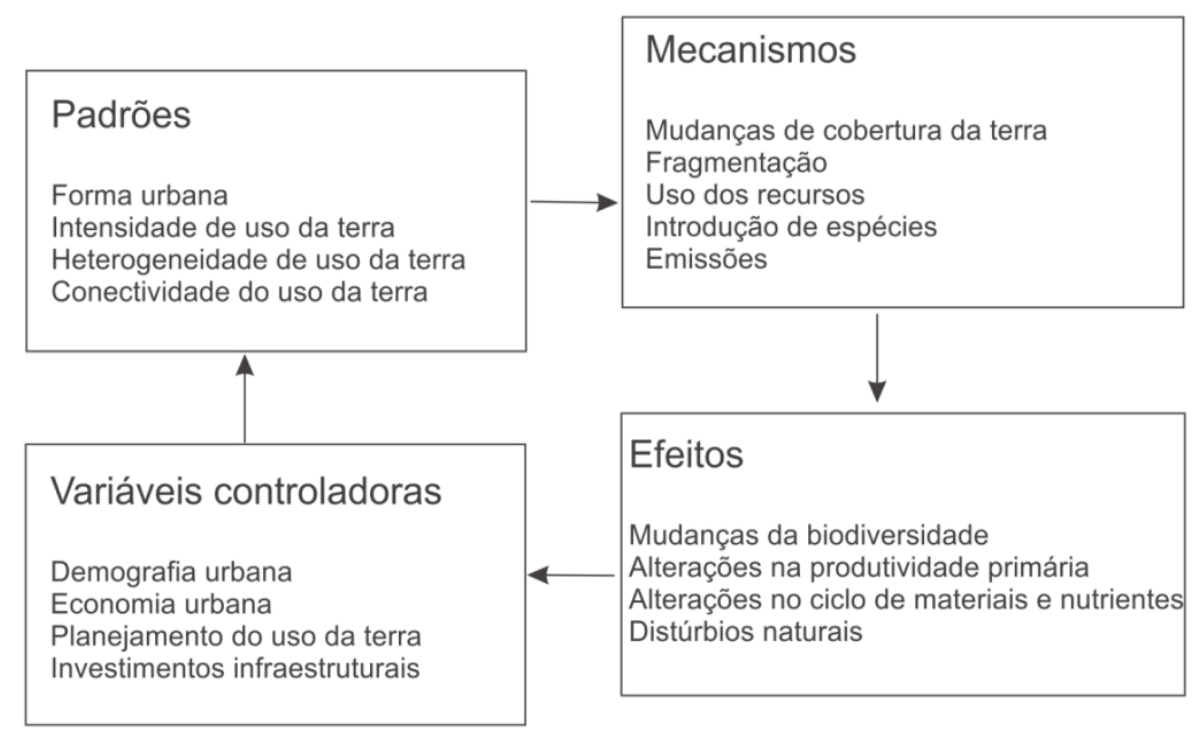

Fonte: adaptado com base em Alberti (2005, p. 175). 
Os efeitos dos padrões de urbanização são diretamente associados à qualidade ambiental local, estando relacionados à fragmentação, ao isolamento, à degradação dos habitats naturais, à simplificação e homogeneização da composição das espécies, à desregulação dos sistemas hidrológicos e à modificação do fluxo energético e dos ciclos de nutrientes (ALBERTI; MARZLUFF, 2004).

Grimm et al (2000), ao interpretar o sistema urbano diante de sua dinâmica de interação funcional, apresentam um modelo conceitual que esquematiza a integração dos sistemas social e ambiental em áreas urbanas (Figura 3). Este esquema dialoga com o anterior, identificando as variáveis junto às caixas e suas interações nas setas.

Figura 3 - Modelo conceitual de interpretação dos processos sociais e ambientais no sistema urbano.

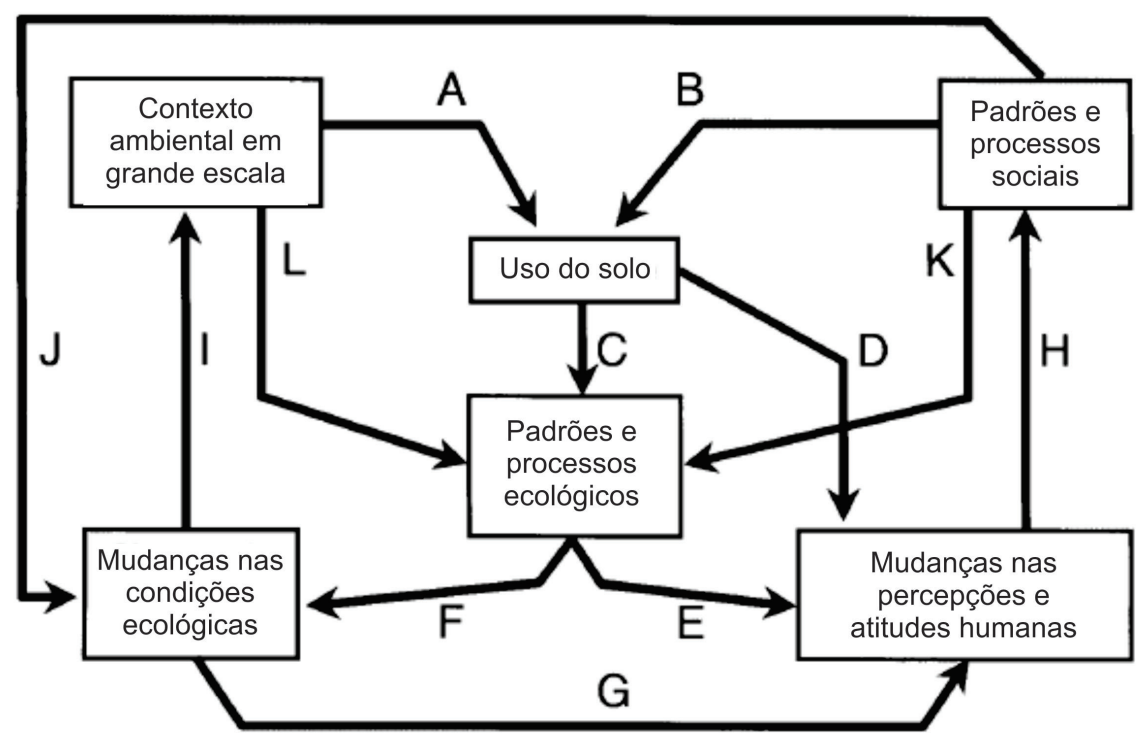

Fonte: adaptado com base em Grimm et al (2000, p.577).

No esquema, "A" representa o contexto ambiental (grandes controles na escala planetária que afetam a questão local) que define a gama de possibilidades para o uso e cobertura da terra, complementado por " $\mathrm{B}$ " que sinaliza as decisões da sociedade e o comportamento humano como controladores indiretos dos processos ecológicos por meio do controle do uso da terra na escala local ou, em alguns casos, influenciando diretamente os processos ecológicos (K) por meio da alteração intencional nos ciclos de matéria e energia.

Este controle de uso da terra, por sua vez, também influencia de forma direta os padrões e processos ecológicos $(\mathrm{C})$. Os seres humanos percebem e reagem às mudanças de uso da terra (D) e às alterações nos padrões e processos ecológicos (E). Em "F", as mudanças nos padrões e processos ecológicos resultam na alteração das condições ecológicas locais (as quais, em última instância, são as principais responsáveis pela regulação das funcionalidades e, por conseguinte, pela qualidade ambiental do sistema). Em "G", tais mudanças das condições ecológicas podem resultar em mudanças de atitudes, percebidas como boas ou ruins pelos humanos.

A partir deste processo de percepção e mudança de atitudes, "H" aponta para uma possibilidade de transformação dos padrões e processos sociais, carregado de possíveis influências no processo de tomada de decisões, renovando parte do ciclo numa perspectiva mais sustentável. Já "I" indica que, considerando a hierarquia do encadeamento entre sistemas em diferentes escalas, as alterações nas condições ecológicas locais resultam em alterações em cascata escalante (CHRISTOFOLETTI, 1999) no contexto ambiental até as escalas mais amplas, da mesma forma que sofre a influência dos controles destas escalas superiores (L), independente do uso da terra local.

Ainda assim, quando uma resposta da sociedade à alteração das condições ecológicas for Geografia Ensino \& Pesquisa, v. 17, n.3, p. 209-228, maio/ago. 2013 considerada necessária, ela pode agir diretamente sobre a qualidade ambiental (J) (GRIMM et al, 2000). 
A incorporação dos indicadores humanos na ordenação ecológica dos espaços urbanos, para além das variáveis biofísicas, pode fornecer um novo enquadramento às categorias tradicionalmente reconhecidas pelos urbanistas, onde conviria retomar critérios próprios à demografia, à sociologia e ao urbanismo (DANSEREAU, 1999), permitindo que estas interações possam ser reinterpretadas na perspectiva de um verdadeiro metabolismo socioambiental.

No que se refere ao papel da vegetação dentro deste metabolismo, é relevante acrescentar que enquanto estratégia de conservação da natureza em áreas urbanas, a manutenção de fragmentos de vegetação possui uma função extremamente importante, possibilitando processos de regulação e auto-ajustamento, auxiliando no controle da qualidade da atmosfera, na regulação térmica, no controle hidrológico e no abastecimento de água, dentre outras funcionalidades ambientais (DIAS, 1997).

Alberti e Marzluff (2004), ao discutirem sobre a resiliência dos ecossistemas urbanos associadas aos padrões de urbanização, sustentam a ideia de que a manutenção dos "serviços ecológicos" no ecossistema urbano pode contribuir com alguns "serviços humanos", sendo estes interdependentes. Os autores (op. cit., 2004, p. 246) afirmam que:

${ }^{2}$ Ehrlich, P. R; Mooney, H. A. Extinction, substitution and ecosystem services. Bioscience, 33, 284-254, 1983.

Daily, G. C. Nature's services: societal dependence on natural ecosystems. Washington: Island Press, 1997.

4 Constanza, R.; D'Arge, R.; DeGroot, R.; Farber, S.; Grasso, M.; Hannon, B.; Limburg, K.; Naeem, S.; O'Neil, R. V.; Paruelo, J.; Raskin, R. G.; Sutton, P.; Van den Belt, M. The value of the world ecosystem services and natural capital. Nature, 387, 253-260, 1997.

Geografia Ensino \& Pesquisa, v. 17, n.3, p. 209-228, set./dez. 2013

Análise da configuração dos fragmentos de cobertura vegetal com base na definição de unidades de paisagem na área urbana de Santa Maria (RS)
Serviços humanos em áreas urbanas tais como moradia, suprimento de água, depósito de resíduos e recreação dependem no ecossistema dos recursos naturais e sua produtividade em longo prazo. Eles também dependem da capacidade do ecossistema de atuar como dissipador na absorção de emissões e resíduos. Ecossistemas também fornecem importantes serviços para a população urbana: eles regulam o clima, controlam inundações e absorvem carbono, para citar alguns (Ehrlich and Mooney, 1983²; Daily, 1997³; Costanza et al., 19974). Serviços humanos dependem dos serviços dos ecossistemas locais e globais porque as cidades importam recursosde áreas distantes. Por outro lado, a capacidade de manter esses serviços localmente e globalmente dependem cada vez mais das atividades humanas e dos padrões de desenvolvimento dos assentamentos humanos.

Neste contexto de padrões de desenvolvimento urbano, inserem-se diversas discussões que abordam a conservação da natureza na cidade. Tian et al (2011) destacam a importância da proteção e criação de espaços verdes urbanos, criticando a sua fragmentação e afirmando que esses não devem ser considerados como entidades isoladas. A conectividade dos fragmentos resulta no padrão em que eles estão configurados dentro da trama urbana. Conforme Jim (1989), que realizou um estudo da distribuição espacial e da forma da vegetação em Hong Kong, os fragmentos de vegetação arbórea em áreas urbanas podem ser classificados em isolados, lineares ou conectados (Figura 4).

De acordo com o autor (op.cit., 1989), as tipologias isoladas são aquelas em que a cobertura vegetal está inserida junto a uma matriz contínua de superfícies impermeáveis, podendo apresentar pequenas unidades isoladas ("dispersas"), pequenos grupos ("agrupadas") ou da agregação de agrupamentos ainda isolados ("agregadas").

As tipologias lineares são aquelas que apresentam uma justaposição de árvores que confluem em determinada direção dominante, podendo ser associadas às árvores alinhadas em calçadas ou nas periferias dos lotes ("retilíneas"), em maiores cinturões acompanhando vertentes naturais ou modificadas ("curvilíneas") e, ainda, quando as árvores formam anéis contínuos ao arredor de pequenos morros ("anelares").

Já as tipologias conectadas são as que apresentam a distribuição de cobertura vegetal arbórea com maior conectividade, geralmente associadas a florestas remanescentes, podendo estar associadas a agrupamentos de árvores interligados em vertentes não edificadas ("reticuladas"), onde copas entrelaçadas formam uma estrutura contínua que envolve lotes edificados separadamente, apresentando mais de $50 \%$ de cobertura vegetal ("ramificadas") ou, por fim, com mais de $75 \%$ da área com cobertura vegetal, que representam áreas florestais com pouco avanço de edificações ("contínuas"). 
Figura 4 - Configurações de distribuição da vegetação arbórea para áreas urbanas.

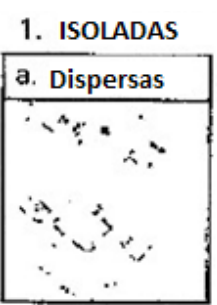

2. LINEARES

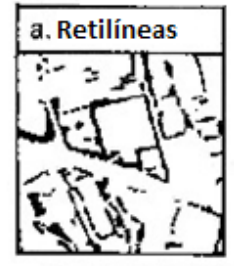

3. CONECTADAS

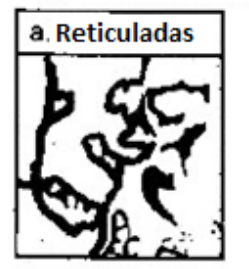

Cobertura vegetal arbórea
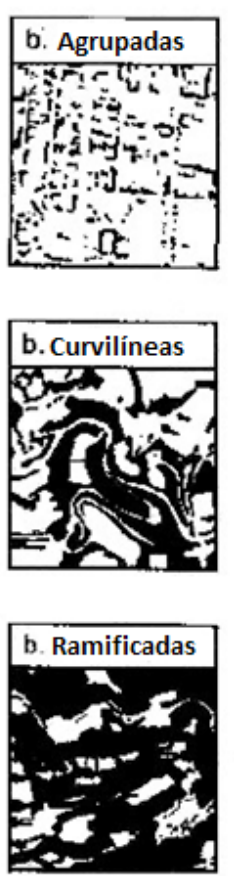

0

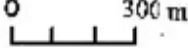

$300 \mathrm{~m}$
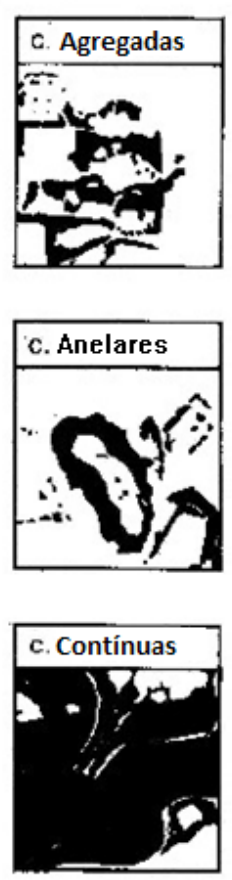

Fonte: adaptado com base em Jim (1989, p.210).

Essas constatações referentes à forma, ao tamanho e à distribuição da vegetação estão extremamente atreladas à qualidade ambiental por ela proporcionada, sendo imprescindíveis no momento de se utilizar a cobertura vegetal como indicador de algumas funcionalidades ambientais. São insuficientes as tentativas de analisar quantitativamente a vegetação sem considerar como os seus fragmentos estão configurados, ou seja, distribuídos e organizados dentro da malha urbana.

Diversos estudos que emergem recentemente diante destes pressupostos podem ser citados aqui, desenvolvidos por geógrafos, biólogos, arquitetos e demais pesquisadores, tais como os trabalhos de Madureira et al (2011) ${ }^{5}$, Tian et al (2011) ${ }^{6}$, Young (2010) ${ }^{7}$ e Escobedo et al (2006) ${ }^{8}$. Essas investigações mostram a relevância de compreender a configuração da vegetação em áreas urbanas para que se possa, assim, contribuir efetivamente com o processo de gestão socioambiental urbana das cidades.

\section{Caracterização da área de estudo}

A cidade de Santa Maria (Figura 5) está situada em uma área de transição geomorfológica entre a Depressão Central do Rio Grande do Sul e a escarpa do Planalto Meridional Brasileiro (ROSS, 2001), possuindo uma formação vegetal transicional entre as paisagens de Mata Atlântica (Floresta Estacional Decidual) e as formações herbáceo-arbustivas do Pampa (MARCHIORI, 2009), estando a parte norte do município inserida dentro da Reserva da Biosfera da Mata Atlântica.

Os estratos florestais, derivados da Floresta Estacional Decidual, estão mais associados às áreas mais úmidas da encosta do planalto, aos morros testemunhos e às margens dos canais de drenagem ou nas suas nascentes, onde os fragmentos arbóreos cercados por gramíneas recebem regionalmente o nome de "capões", encimando coxilhas suaves em meio a extensas planícies aluviais.

A partir da ocupação inicial de uma destas coxilhas em fins do sec. XVIII, o adensamento populacional foi se acentuando na cidade, especialmente durante o século XX, e com ele a expansão da estrutura horizontal de edificações, que suprimiram as florestas dos fundos de vale, substituindo-as por poucos exemplares exóticos de acompanhamento viário.

5 Analisam a estrutura verde e a evolução do planejamento na área urbana da cidade de Porto (Portugal), considerando a questão da alteração do número, tamanho e conectividade dos fragmentos durante o século XX de acordo com a evolução das políticas de sucessão de planos diretores.

${ }^{6}$ Apresentam um estudo da fragmentação da vegetação em Hong Kong, identificando as áreas de menos e maior conectividade dos fragmentos.

${ }^{7}$ Discute a gestão de espaços verdes municipais para a manutenção de serviços ecossistêmicos em áreas urbanas.

\footnotetext{
Abordam a gestão das florestas urbanas públicas, relacionando com as condições socioeconômicas em Santiago (Chile).
}

Geografia Ensino \& Pesquisa, v. 17, n.3, p. 209-228, maio/ago. 2013.

Alves, D. B.; Figueiró, A. S. 
Apesar da decadência do setor de ferrovias, que esteve diretamente associado ao crescimento populacional entre o final do século XIX e princípio do século XX, outros fatores contribuíram para este adensamento, tais como a instalação de algumas unidades do Exército Brasileiro e também da Aeronáutica Brasileira (com uma Base Aérea, construída em 1970), além da instalação da Universidade Federal de Santa Maria (1960), que acabaram atraindo um grande contingente populacional para a cidade. Junto a essas instituições, se configurou uma extensa rede de serviços e comércio, que representa o principal setor econômico da cidade atualmente, com destaque regional.

Figura 5 - Localização de Santa Maria no estado do Rio Grande do Sul, com o perímetro urbano em destaque.

\section{Santa Maria-RS}

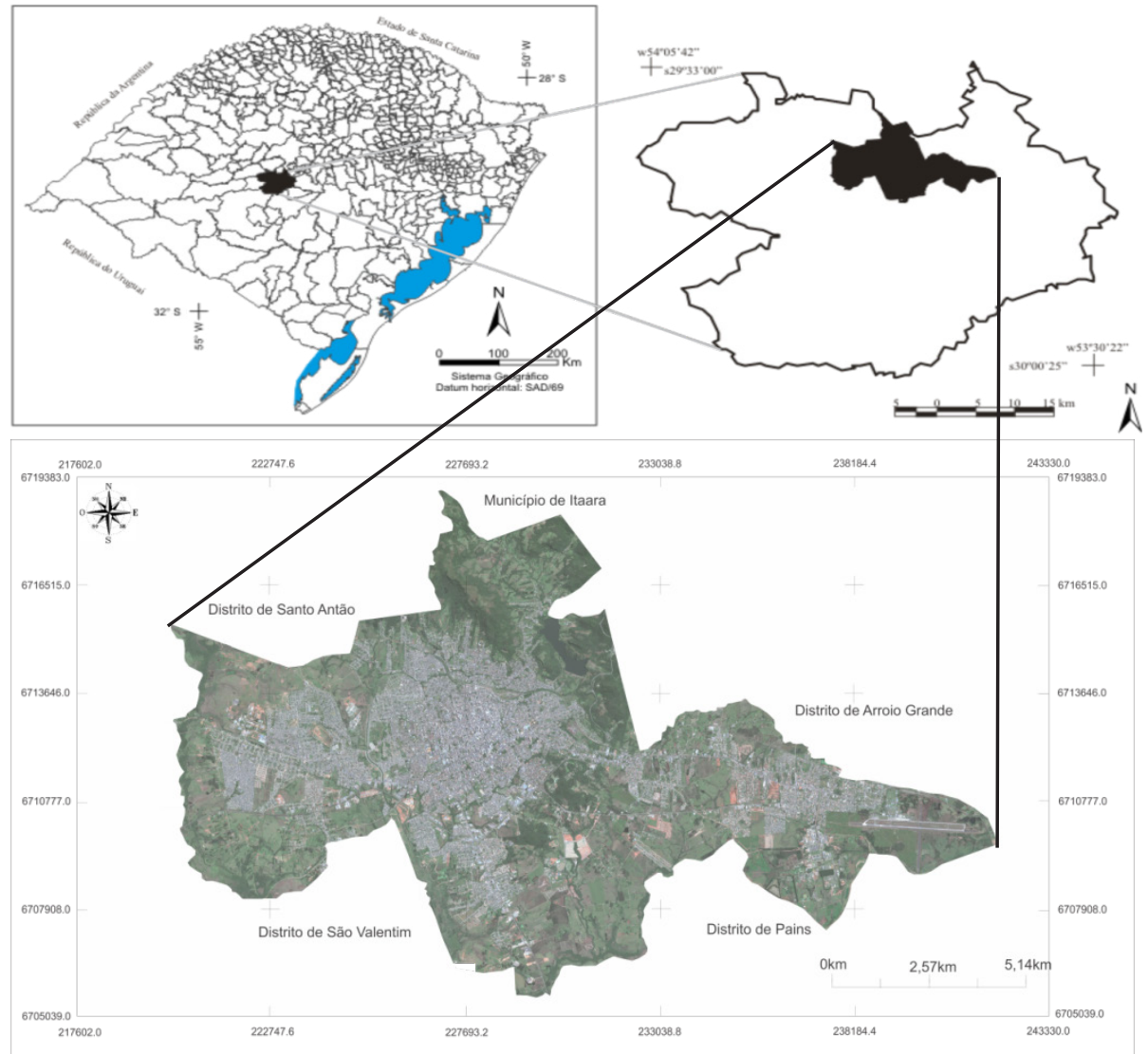

Fonte: organizado pelos autores. A imagem do perímetro urbano foi extraída do software Google Earth, e correspondem a imagem GeoEye de 21/09/2011.

Esse contexto de atração populacional resulta na situação atual da cidade, que apresenta a população de 261.027 habitantes (segundo censo IBGE, 2010) e uma paisagem urbana bem edificada. Seguindo o panorama do crescimento acelerado das cidades de porte médio brasileiras, Santa Maria é um exemplo de cidade em que o verde urbano foi sendo suprimido, dando lugar às edificações e às vias de circulação.

\section{Metodologia}

A proposta metodológica se desenvolve com base na abordagem geossistêmica da pai-

Geografia Ensino \& Pesquisa, v. 17, n.3, p. 209-228, set./dez. 2013

Análise da configuração dos fragmentos de cobertura vegetal com base na definição de unidades de paisagem na área urbana de Santa Maria (RS) sagem, desenvolvida por Bertrand (1972). Considerando que a cidade corresponde a uma estrutura simbiótica entre uma natureza manejada e uma artificialidade humana, contrastando (seja pela sua estrutura, seja pelos fluxos de matéria e energia que por ela circulam) com as estruturas seminaturais das áreas rurais do entorno, optou-se pelo uso do limite urbano como sendo o do recorte geosistêmico, dentro do qual um mosaico de unidades subordinadas (Geofácies) se distribuem conforme os diferentes estados de antropização do sistema e as consequentes entradas diferenciadas de matéria e energia no tempo e no espaço. 
Este Geossistema urbano, por sua vez, está contido dentro da transição de duas grandes Regiões Naturais: a Depressão Central e o Planalto Meridional Brasileiro.

Considerando esses pressupostos e os objetivos traçados na investigação, buscou-se delimitar as diferentes Geofácies dentro do Geossistema urbano de Santa Maria, analisandose a configuração dos fragmentos de cobertura vegetal e o grau de impermeabilização do solo associados a cada uma dessas unidades de paisagem. Como critérios para a delimitação das Geofácies considerou-se a combinação da configuração da estrutura horizontal de cobertura vegetal arbórea (classificada de acordo com a proposta de Jim, 1989) com os diferentes padrões de urbanização associados (em áreas densamente edificadas, menos densamente edificadas, às margens de canais de drenagem, em áreas de morros ou campos e áreas de transição com atividades de produção rural). Tomou-se, assim, estas características como indicadoras dos fluxos de matéria-energia-informação a que as diferentes unidades de paisagem estão submetidas.

Para a obtenção das características de configuração da cobertura vegetal arbórea e a interpretação dos diferentes tipos de padrões de urbanização, contou-se com a classificação da imagem GeoEye de 21/09/2011. A imagem foi classificada junto ao software Spring, com um algoritmo por leitura de pixel, baseado no classificador Maxver (Máxima verossimilhança) a partir da aquisição de polígonos amostrais de treinamento e teste, que passou posteriormente por um processo de supervisão e otimização. Para isso, definiram-se quatro classes temáticas: Cobertura Vegetal Arbórea; Cobertura Vegetal Herbácea e Arbustiva; Espaços Construídos; e Rede de drenagem.

Na primeira classe, como o título sugere, incluem-se as áreas com presença de cobertura vegetal de porte arbóreo. A segunda classe contém as áreas de cobertura vegetal de porte herbáceo e arbustivo. Nesta classe ainda inclui-se algumas áreas de uso rural situadas em algumas zonas de transição da área urbana do distrito sede de Santa Maria com a área rural. A terceira classe, denominada "Espaços Construídos", incorpora todas as áreas edificadas e vias de circulação, incluindo-se ainda as áreas de solos expostos. A rede de drenagem inclui os canais de água situados na zona urbana do distrito sede, e os seus reservatórios de água.

De acordo com as observações da combinação dos critérios acima descritos, foram pré-definidas seis diferentes Geofácies, passando-se a delineá-las junto ao software Spring, a partir da digitalização poligonal, em um plano de informação de um modelo de dados temático.

Delineadas as Geofácies, passou-se a analisar a configuração dos fragmentos de cobertura vegetal de cada uma das seis unidades, considerando ainda as tipologias de distribuição de Jim (1989), gerando-se as medidas de classes, a porcentagem de cobertura vegetal arbórea, herbácea e arbustiva, que permitiram discutir possíveis estratégias de conservação da natureza para a paisagem urbana de Santa Maria.

\section{Resultados e discussões}

Considerando a forma como estão estruturados os fragmentos arbóreos de vegetação, e o padrão de urbanização em que estão inseridos, foram delineadas seis Geofácies (Figura 6) dentro do Geossistema urbano': Geofácie de morros do rebordo; Geofácie de morros testemunhos; Geofácie de matas galerias; Geofácie de áreas mais densamente edificadas; Geofácie de áreas menos densamente edificadas; Geofácies de áreas rururbanas.

Associando características de isolamento de fragmentos arbóreos junto a um padrão de urbanização de maior adensamento de edificações, destaca-se a Geofácie das áreas mais densamente edificadas, que representa aproximadamente $20 \%$ da área urbana do município. Esta Geofácie, com áreas distribuídas principalmente nas porções centro-oeste e oeste do Geossistema urbano, apresenta um alto nível de isolamento dos fragmentos de cobertura vegetal, onde se observa que os espaços verdes foram substituídos em grande parte por áreas impermeabilizadas, com reiterados problemas em termos da funcionalidade térmica e hidrológica destas áreas.

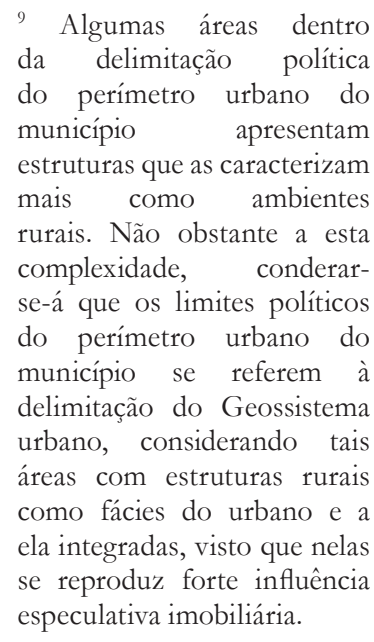

Geografia Ensino \& Pesquisa, v. 17, n.3, p. 209-228, maio/ago. 2013.

Alves, D. B.; Figueiró, A. S. 
Dentre as Geofácies que apresentam uma boa configuração da vegetação arbórea, com fragmentos mais conectados e contínuos, destaca-se a Geofácie de morros do rebordo. Esta Geofácie, presente na porção norte do mapa, ocupa cerca de 12\% do Geossistema urbano, apresentando uma boa configuração da estrutura arbórea, sendo a principal responsável pelo elevado índice de arborização do conjunto do perímetro urbano da cidade.

Nas nascentes e nas margens dos canais de água observa-se a Geofácie de mata galeria, onde a vegetação acompanha os meandros dos canais de água, e muitas vezes expandem-se nos arredores, especialmente nas áreas menos densamente ocupadas.

Figura 6 - Mapa das Geofácies da área urbana de Santa Maria, com destaque para recortes da imagem Geoeye, de 21909/2011, que permitem visualizar a estrutura geoecológica em determinadas áreas da cidade.
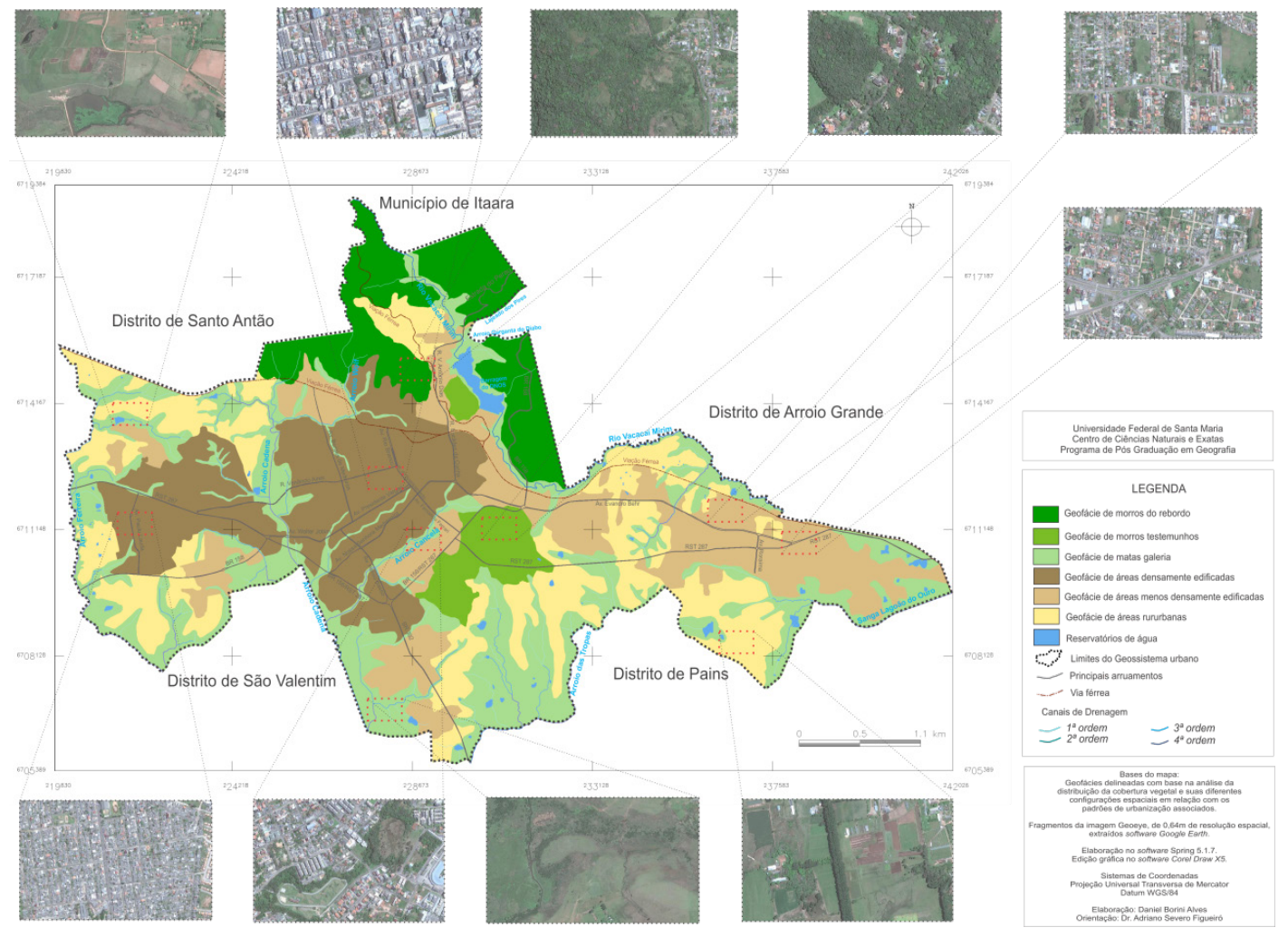

Fonte: elaborado pelos autores.

Com a definição dessas unidades de paisagem, fica mais clara a compreensão da distribuição da cobertura vegetal na área urbana de Santa Maria, sendo que as porcentagens de cobertura vegetal por Geofácies denotam vínculos com os padrões de urbanização ali predominantes. A Tabela 1 apresenta a distribuição quantitativa da subdivisão de classes temáticas de uso e cobertura da terra de acordo com as unidades de paisagem identificadas.

Percebe-se que a porcentagem de cobertura vegetal arbórea para toda a área urbana representa, aproximadamente, $32,9 \%$ (3.912,82 ha) de arborização. Porém, ao observar-se a distribuição dessa cobertura entre as diferentes Geofácies, verifica-se que ela não apresenta uma grande uniformidade, já que enquanto na Geofácie de morros do rebordo e Geofácie de morros

Geografia Ensino \& Pesquisa, v. 17, n.3, p. 209-228, set./dez. 2013

Análise da configuração dos fragmentos de cobertura vegetal com base na definição de unidades de paisagem na área urbana de Santa Maria(RS) testemunhos a arborização é de $75,66 \%$ e 62,04\%, respectivamente, as demais Geofácies apresentam porcentagens inferiores a 33,09\%, sendo que na Geofácie de áreas densamente edificadas o valor foi de $17,04 \%$, o que nos leva a concluir que a adoção de um índice único de cobertura vegetal para todo o espaço urbano não representa um indicador adequado para a avaliação da qualidade do sistema, devendo-se analisar as discrepâncias internas existentes. 
Tabela 1 - Classes de uso e cobertura da terra (2011) no interior das Geofácies.

\begin{tabular}{|c|c|c|c|c|c|c|c|c|c|c|}
\hline \multirow{3}{*}{$\begin{array}{l}\text { Unidade de } \\
\text { paisagem }\end{array}$} & \multirow{2}{*}{\multicolumn{2}{|c|}{ Ár ea total }} & \multicolumn{8}{|c|}{ Uso e cobertura da terra } \\
\hline & & & \multicolumn{2}{|c|}{$\mathrm{EC}$} & \multicolumn{2}{|c|}{ CVA } & \multicolumn{2}{|c|}{ CVHA } & \multicolumn{2}{|c|}{$\mathrm{RD}$} \\
\hline & (ma) & (\%) & (na) & (\%) & (na) & (\%) & (na) & (\%) & (ha) & (\%) \\
\hline $\begin{array}{c}\text { Geofácie dos } \\
\text { morros do rebordo }\end{array}$ & $1.573,59$ & 12,16 & 57,74 & 3,67 & $1.190,54$ & 75,66 & 323,21 & 20,54 & 2,1 & 0,13 \\
\hline $\begin{array}{c}\text { Geofácie de morros } \\
\text { testemunhos }\end{array}$ & 514,51 & 3,98 & 61,4 & 1193 & 31921 & 62,04 & 133,6 & 25,97 & 0,3 & 0,06 \\
\hline $\begin{array}{c}\text { Geofácie de áreas } \\
\text { densamente } \\
\text { edificadas }\end{array}$ & 2623,3 & 20,26 & $1.802,83$ & 68,72 & 44696 & 17,04 & 373,4 & 14,23 & 0,11 & 0,00 \\
\hline $\begin{array}{c}\text { Geofácie de áreas } \\
\text { menos densamente } \\
\text { edificadas }\end{array}$ & $2.268,3$ & 17,52 & $1.060,78$ & 46,77 & 543,52 & 23,96 & 663,66 & 29,26 & 0,34 & 0,01 \\
\hline $\begin{array}{c}\text { Geofácie de matas } \\
\text { galeria }\end{array}$ & $3.488,23$ & 26,94 & 499,93 & 14,33 & 1154,1 & 33,09 & $1.697,58$ & 48,67 & 136,62 & 3,92 \\
\hline $\begin{array}{l}\text { Geofacie de áreas } \\
\text { mururbanas }\end{array}$ & 2477,87 & 19,14 & 430,14 & 17,36 & 604,91 & 24,41 & $1.433,76$ & 57,86 & 9,06 & 0,37 \\
\hline TOTAL & 129458 & 100 & 3912,82 & 30,22 & $4.259,24$ & 32,90 & $4,625,21$ & 35,73 & 148,53 & 1,15 \\
\hline
\end{tabular}

Uso e cobertura da terra - EC = Espaços Construidos; CVA= Cobertura Vegetal Arbórea; CVHA= Cobertura Vegetal Herbácea on Arbustiva; $R D=$ Rede de Drenagem. Para cada classe indica-se a área ocupada (ba) e a proporção de área ocupada (\%) em relação à área total da Geofácie.

Fonte: elaborado pelos autores.

A Geofácie de morros do rebordo (Figura 7) corresponde às áreas de escarpa arenito-basálticas a norte do perímetro urbano do município, situadas nas encostas do Planalto Meridional Brasileiro, que possuem fragmentos de vegetação de porte arbóreo bem estruturados, com alto grau de conectividade.

Figura 7 - Uso e cobertura da terra na Geofácie de morros do rebordo, revelando a distribuição de cobertura vegetal da área.

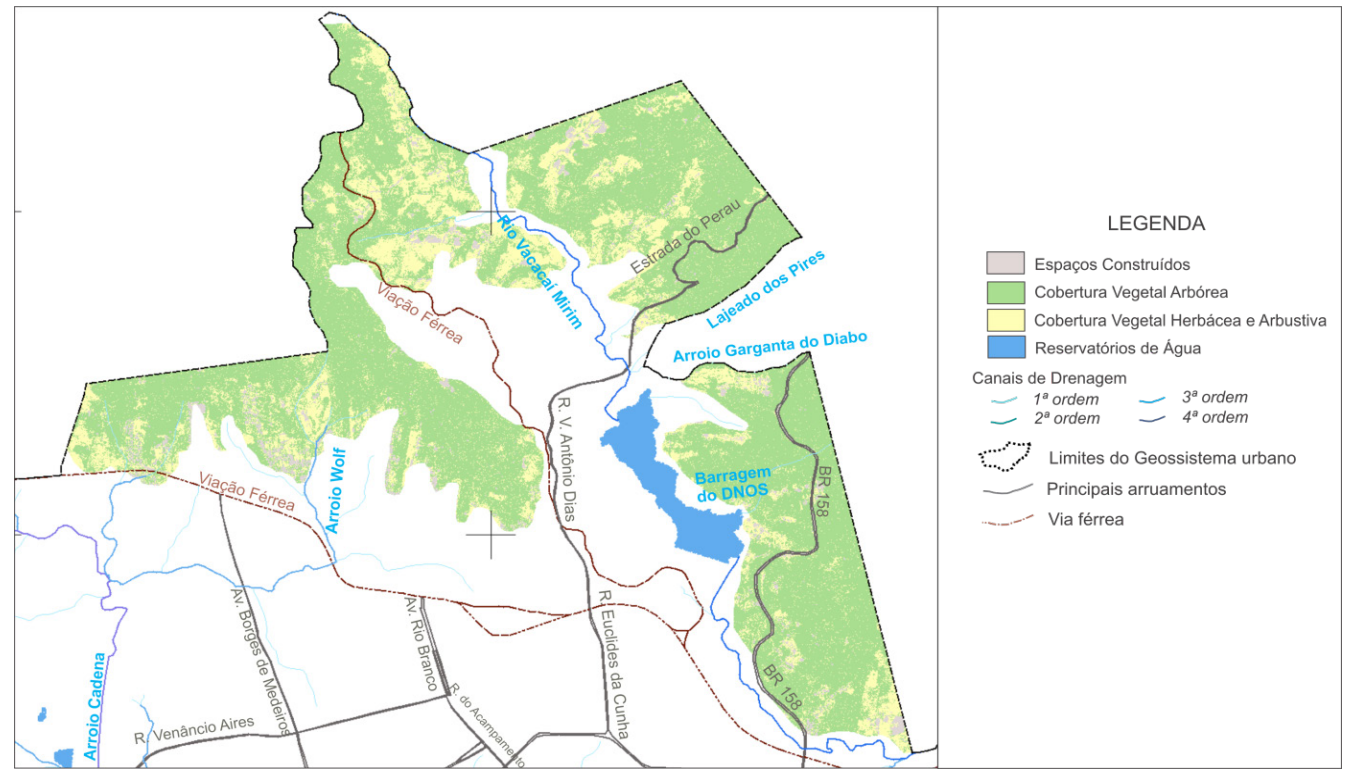

Fonte: elaborado pelos autores.

O avanço das edificações nessas áreas é pouco expressivo, limitado muito em função das características do terreno, tais como a declividade e a ocorrência de depósitos de tálus inconsolidados. Apesar disso, esta questão não impede a existência de inúmeros casos de conflitos legais dentro desta unidade de paisagem, envolvendo ocupação de áreas de APP ou construção em áreas de risco. A criação de unidades de conservação, como discutido no trabalho de Nascimento e Foleto (2010), pode contribuir plenamente com esta perspectiva, na contenção da expansão urbana, e deve ter a Reserva da Biosfera da Mata Atlântica como referência na criação e zoneamento da Área de Proteção Ambiental do Vacacaí-Mirim/RS.

Geografia Ensino \& Pesquisa, v. 17, n.3, p. 209-228, maio/ago. 2013.

Alves, D. B.; Figueiró, A. S. 
Estas áreas estão contidas dentro da Reserva da Biosfera da Mata Atlântica. Como se pode observar na tabela as características desta Geofácie acabam revelando uma alta porcentagem de cobertura vegetal arbórea na área $(75,66 \%)$ e uma baixa porcentagem de espaços construídos (3,67\%).

A Geofácie de morros testemunhos (Figura 8) corresponde às áreas dos morros Mariano da Rocha, Cerrito (Figura 9) e Cechela, relacionados ao recuo da escarpa, em que a vegetação arbórea ainda permanece bem configurada e conectada, com eventuais descontinuidades vinculadas ao avanço de algumas áreas residenciais e outras áreas institucionais.

Figura 8 - Uso e cobertura da terra na Geofácie de morros testemunhos, revelando a distribuição de cobertura vegetal da área.

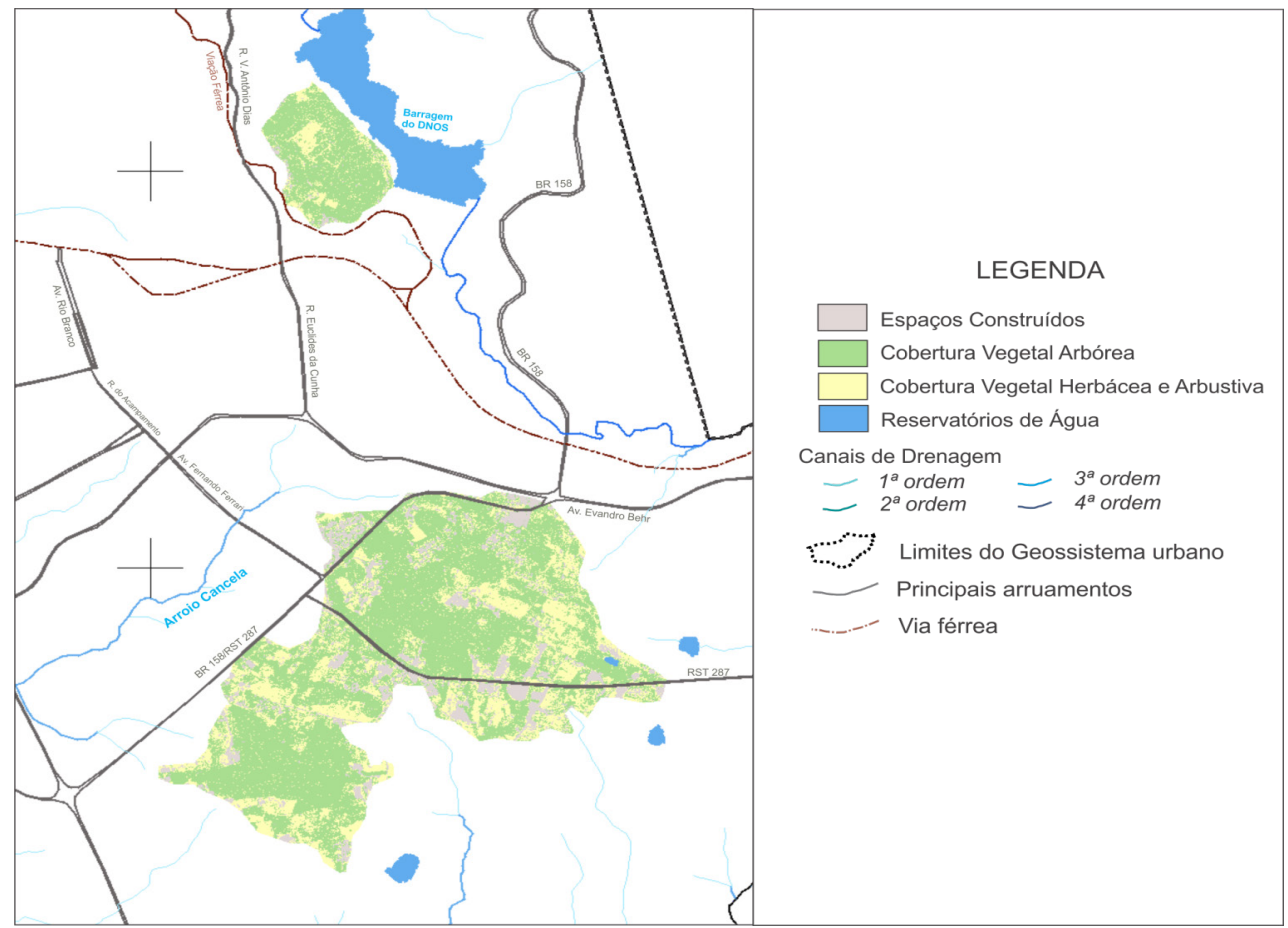

Fonte: elaborado pelos autores.

Figura 9 - Ao fundo das fotografias o Morro Cerrito (à esquerda) e o Morro Mariano da Rocha (à direita). Observa-se nessas áreas um alto grau de arborização e pouco avanço das áreas edificadas.

Geografia Ensino \& Pesquisa, v. 17, n.3, p. 209-228, set./dez. 2013

Análise da configuração dos fragmentos de cobertura vegetal com base na definição de unidades de paisagem na área urbana de Santa Maria (RS)

ISSN 2236-4994
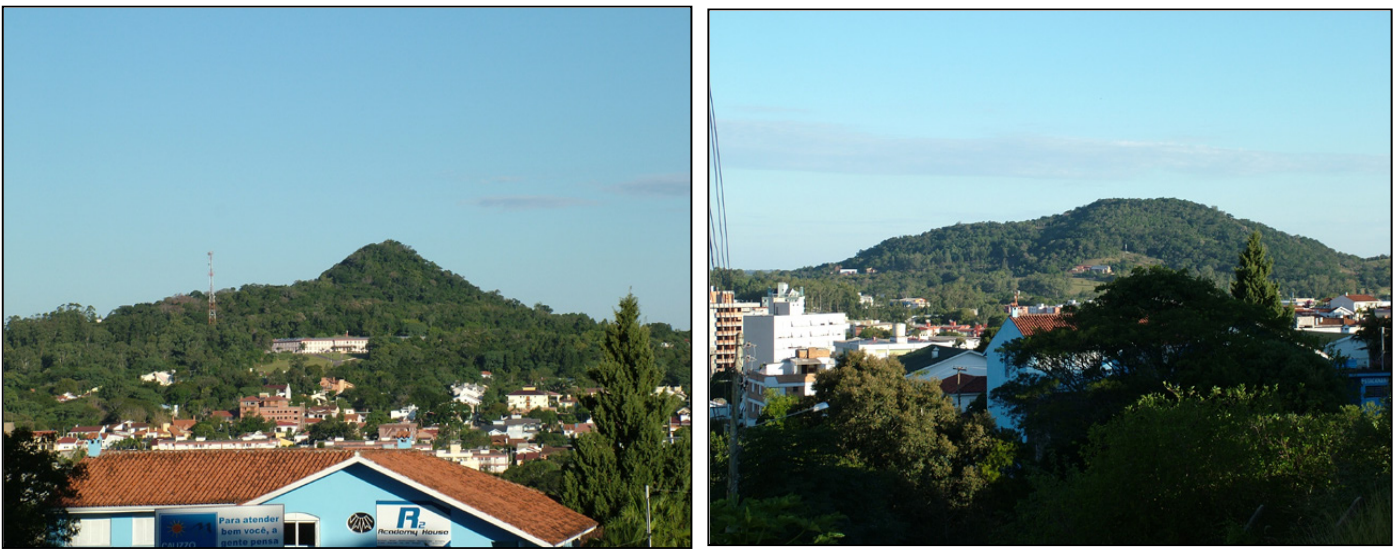

Fonte: Scipione e Santos, 2004.

Nessas áreas de avanço das estruturas edificadas, o padrão de urbanização apresenta, em grande parte, lotes residenciais com pouca impermeabilização do solo em grandes pátios onde se mantém áreas livres e cobertura vegetal arbórea. O índice 
de cobertura vegetal arbórea da Geofácie é pouco inferior ao da Geofácie de morros do rebordo, com uma porcentagem de $62,04 \%$, com uma área de espaços construídos ocupando $11,93 \%$ do total desta unidade.

Em que pese a grande cobertura arbórea, esta unidade de paisagem requer medidas especiais de proteção, devido aos aspectos especulativos ligados à ideia de um dos últimos "redutos de natureza" em meio à cidade artificializada. Além disso, o progressivo isolamento a que estes fragmentos têm sido submetidos pela artificialização do entorno, indica a necessidade de um melhor planejamento das relações heterárquicas entre esta unidade e as vizinhas, especialmente na perspectiva de se desenhar corredores de conexão que garantam a sobrevivência das espécies existentes nestes grandes fragmentos.

Outra unidade de paisagem individualizada é a Geofácie de Matas Galeria (Figura 10), que corresponde às áreas próximas aos cursos de água e seus arredores, onde a presença da vegetação arbórea se dá muito em função da umidade dos canais, possuindo, portanto, uma configuração mais linear.

Figura 10 - Uso e cobertura da terra na Geofácie de matas galeria, revelando a distribuição de cobertura vegetal da área.

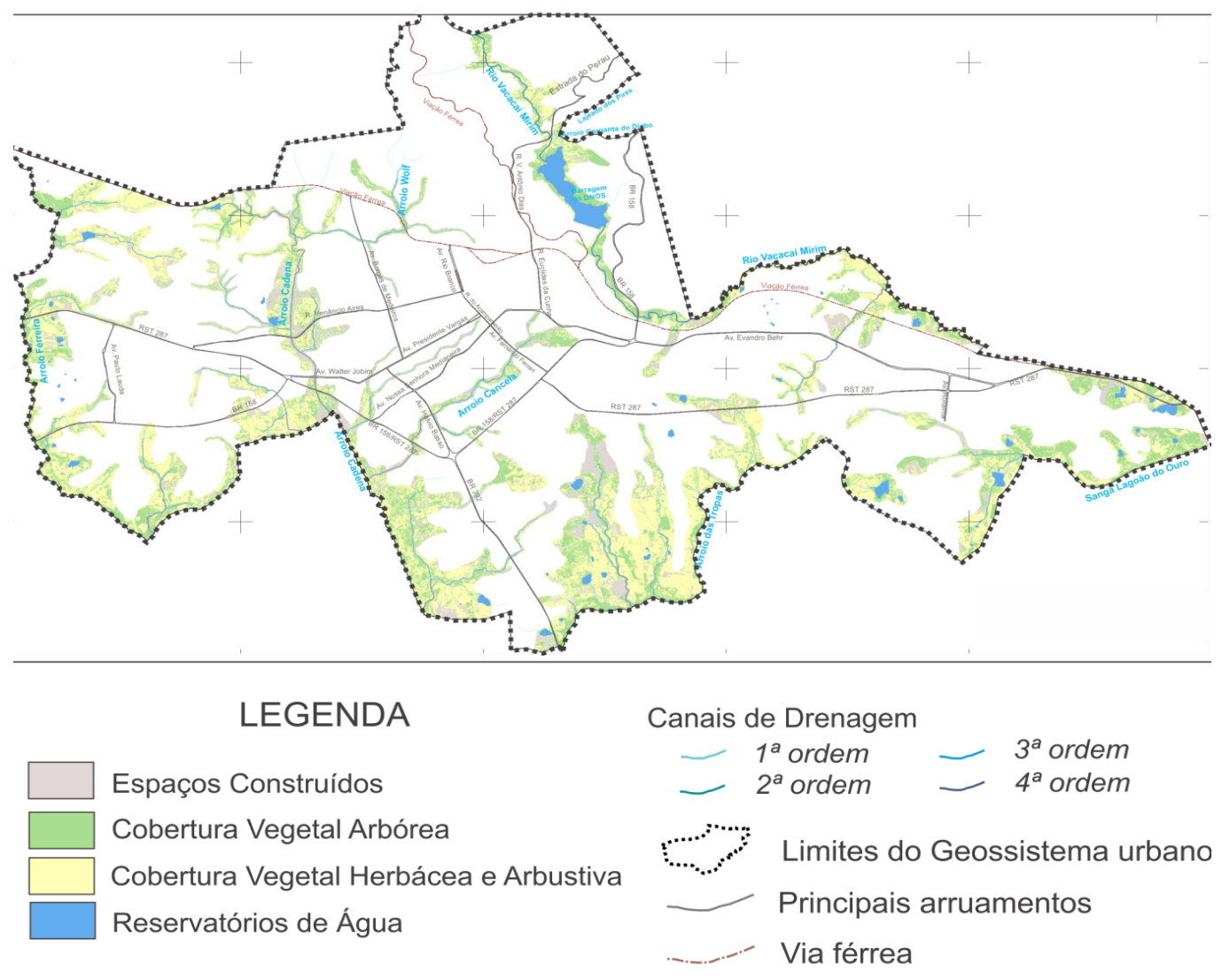

Fonte: elaborado pelos autores.

Alguns canais apresentam uma melhor distribuição da vegetação em relação aos outros, muito em função dos padrões de urbanização associados, como descrito a seguir:

* Próximo das nascentes e do leito do Arroio Ferreira: Localizado no extremo oeste do perímetro urbano do município, correndo de norte para sul, o Arroio Ferreira delimita o perímetro urbano do município a oeste. A vegetação aparece bem configurada, onde os fragmentos arbóreos acompanham o canal do arroio e se estendem pelos seus arredores, apresentando pouco avanço das áreas edificadas, sendo o padrão de urbanização de residências dispersas em meio a áreas Geografia Ensino \& Pesquisa, v. 17, n.3, p. 209-228, maio/ago. 2013

Alves, D. B.; Figueiró, A. S. onde há predomínio de cobertura vegetal. 
* Próximo das nascentes e do leito do Arroio Cadena: Localizado a centro-oeste do município, correndo de norte para sul, as nascentes e o leito do Arroio Cadena apresentam algumas diferenciações quanto à configuração da vegetação arbórea a ela associada. Nas nascentes, a vegetação aparece bem estruturada, acompanhando o canal, principalmente na margem direita. Nas nascentes da margem esquerda, observam-se maiores avanços das áreas edificadas, apresentando fragmentos mais isolados. Ao longo do leito do arroio, canalizado a céu aberto, as áreas de vegetação são pouco estruturadas, onde o avanço das áreas edificadas resulta num isolamento de determinados fragmentos, principalmente nas áreas ao redor dos canais que alimentam o arroio, como a Sanga do Hospital, que envolve áreas de alta densidade demográfica.

*Próximo das nascentes e do leito da Sanga do Lagoão do Ouro: Localizada no extremo leste de Santa Maria, percorrendo em grande parte os limites da área urbana do município. A vegetação arbórea está bem configurada na área de captação de água da Sanga, ao longo dos canais de água e seus arredores. O padrão de urbanização apresenta também residências mais dispersas, inclusive associadas a alguns lotes com características rururbanas.

* Próximo das nascentes e do leito do Arroio Passo das Tropas: Localizado nas áreas a centro-sul do município, nas nascentes e nas proximidades do leito do Arroio Passo das Tropas. A vegetação permanece bem configurada, acompanhando os meandros dos canais. O quadro é semelhante ao observado próximo das nascentes e do leito da Sanga do Lagoão do Ouro, com poucas áreas edificadas associadas a residências em lotes rururbanos.

* Arredores do Rio Vacacaí-Mirim: O rio Vacacaí-Mirim corre pela região norte da área urbana do município, na direção sudeste, sendo interrompido em seu percurso pela Barragem do DNOS. O prosseguimento do canal delimita parte da área urbana a nordeste da cidade até o extremo leste do município. A cobertura vegetal arbórea acompanha parte dos meandros do rio, mas apesar do pouco avanço das áreas edificadas, grande parte do canal tem suas margens em situações fragilizadas.

* Próximo das nascentes e no leito do Arroio Cancela: Localizado nas proximidades do Morro Cerrito, no centro-leste da área urbana, e prosseguindo até desaguar no Arroio Cadena, o Arroio Cancela e seus arredores apresentam em grande parte do seu leito, apesar de pressionado pela especulação imobiliária nos seus arredores, uma configuração de fragmentos de vegetação arbórea que acompanha o canal linearmente, formando a mata galeria do arroio, bastante fragilizada nas proximidades dos espaços densamente ocupados.

Esse conjunto de áreas que possuem matas galerias nos arredores dos canais de drenagem é individualizado muito em função da necessidade de estratégias de manejo específicas para gestão de suas fragilidades, a fim de conservar os serviços ecossistêmicos ali existentes. Além disso, esta unidade de paisagem é fundamental para que se possa estabelecer as conexões discutidas acima entre os fragmentos dos Morros Testemunhos e as áreas-fonte localizadas nas encostas do planalto, dentro da Reserva da Biosfera da Mata Atlântica. Dentro dessa unidade de paisagem cerca de 33\% representam áreas de cobertura vegetal arbórea, e aproximadamente $49 \%$ de cobertura vegetal herbácea e arbustiva.

A Geofácie de áreas densamente edificadas (Figura 11) corresponde às áreas de maior adensamento dos espaços construídos, situados na região central e oeste da zona urbana. As áreas de cobertura vegetal arbórea estão configuradas nessa Geofácie de forma isolada e dispersa, onde os raros fragmentos pouco se conectam. Ao concentrar muitas áreas edificadas,

Geografia Ensino \& Pesquisa, v. 17, n.3, p. 209-228, set./dez. 2013

Análise da configuração dos fragmentos de cobertura vegetal com base na definição de unidades de paisagem na área urbana de Santa Maria (RS) essas áreas da cidade apresentam fluxos mais dinâmicos de matéria, energia e informação, que individualizam a Geofácie em relação às demais. A classe de espaços construídos acaba sendo a que ocupa a maior proporção nessa Geofácie, com cerca de $68 \%$ de áreas edificadas. A presença de espécies exóticas, a falta de regulação térmica e hidrológica, além da baixa retenção de poeiras, têm nesta unidade de paisagem a sua maior expressão dentro do município. 
Figura 11 - Uso e cobertura da terra na Geofácie de áreas densamente edificadas, revelando a distribuição de cobertura vegetal da área.

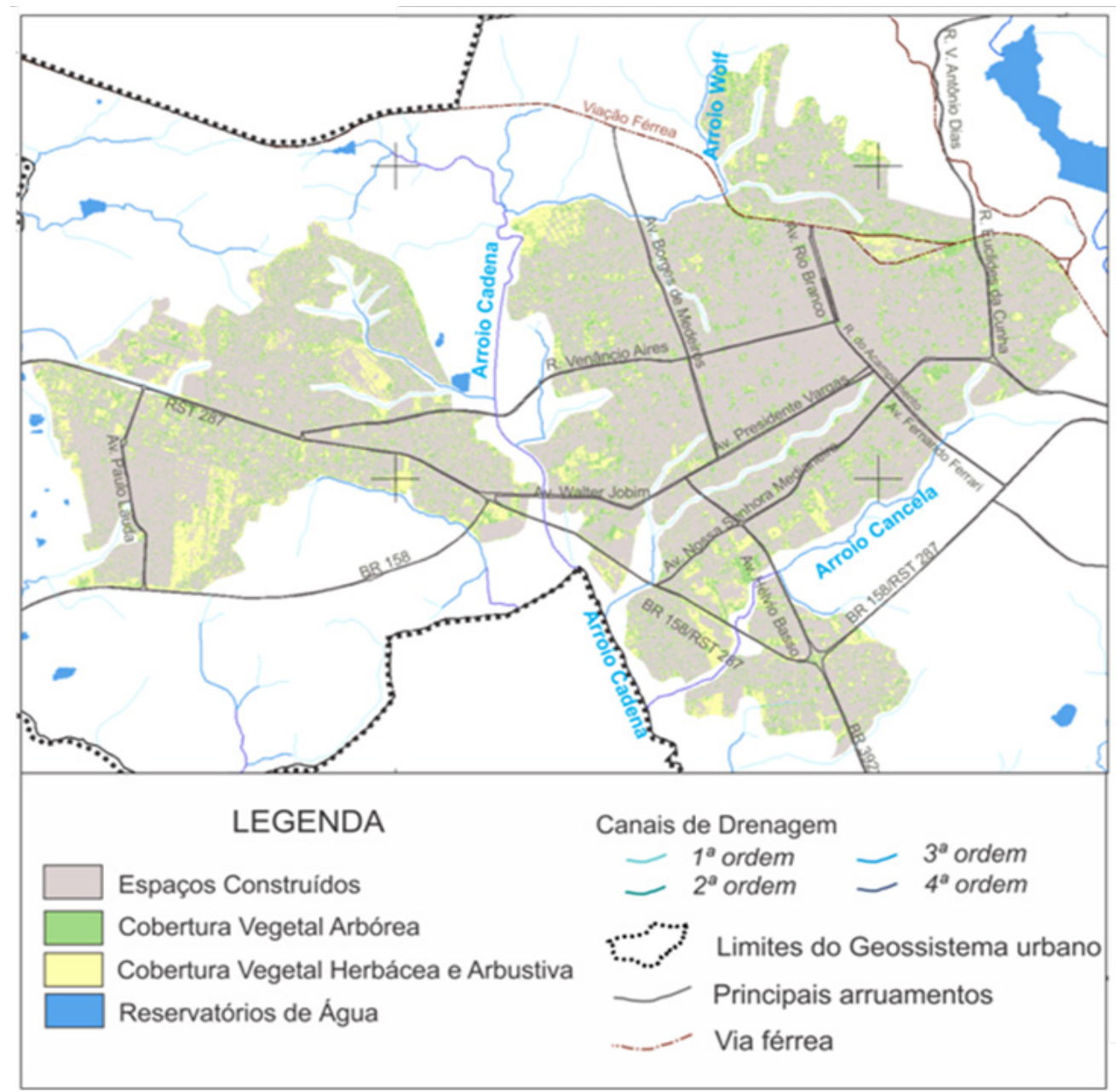

Fonte: elaborado pelos autores.

Para esta Geofácie, que apresenta um panorama de alto adensamento de edificações, acredita-se que uma política pública voltada à manutenção das áreas livres restantes, poderá contribuir não apenas para melhores condições de conservação da natureza, como também para a geração de alternativas de lazer dentro das áreas mais centrais da cidade. Além disso, se deveriam pensar em incentivos do poder público municipal para a adoção de telhados verdes, principalmente nas zonas mais adensadas com presença de edifícios, que predominam nessa unidade de paisagem. É importante destacar que junto a essa Geofácie estão localizados os bairros centrais da cidade, que tiveram perdas significativas de cobertura vegetal nas últimas décadas, exigindo atenção especial do poder público a essas áreas.

A Geofácie de áreas menos densamente edificadas (Figura 12) corresponde às áreas com uma densidade de edificações menor se comparada à classe anterior, referindo-se às zonas periféricas da área urbana, com padrões de urbanização predominantemente residencial. A vegetação arbórea também aparece com uma configuração isolada dentro desta Unidade, apresentando algumas áreas em que a vegetação apresenta alguns fragmentos maiores e com algum grau de conectividade (como, por exemplo, nas das áreas edificadas a centro-leste e leste da área urbana). Devido a essas características, observa-se que a classe de espaços construídos ocupa cerca de $48 \%$ do total da área da Geofácie, contra $24 \%$ de cobertura vegetal arbórea e outros $29 \%$ de cobertura vegetal herbácea e arbustiva.

Geografia Ensino \& Pesquisa, v. 17, n.3, p. 209-228, maio/ago. 2013.

Alves, D. B.; Figueiró, A. S. 
Apesar disso, esta unidade de paisagem é uma das que se encontra sob a maior ameaça, considerando que a parte leste da zona urbana corresponde hoje a uma das áreas de maior crescimento urbano, com grande velocidade no processo de impermeabilização do solo. É de se esperar, portanto, que nos próximos anos esta seja a unidade de paisagem com maior transformação das estruturas ecológicas dentro do município, fato este que deveria servir de alerta aos gestores públicos. Assim, é essencial que se atente especialmente para o percentual mínimo de área livre a ser exigido dentro dos condomínios que tem sido planejados, bem como se limite o gabarito de construção destas áreas, visando conter o processo especulativo dentro de uma unidade de paisagem que é estratégica como "buffer zone" entre a floresta de encosta e as áreas mais densamente construídas.

Figura 12 - Uso e cobertura da terra na Geofácie de áreas densamente edificadas, revelando a distribuição de cobertura vegetal da área.

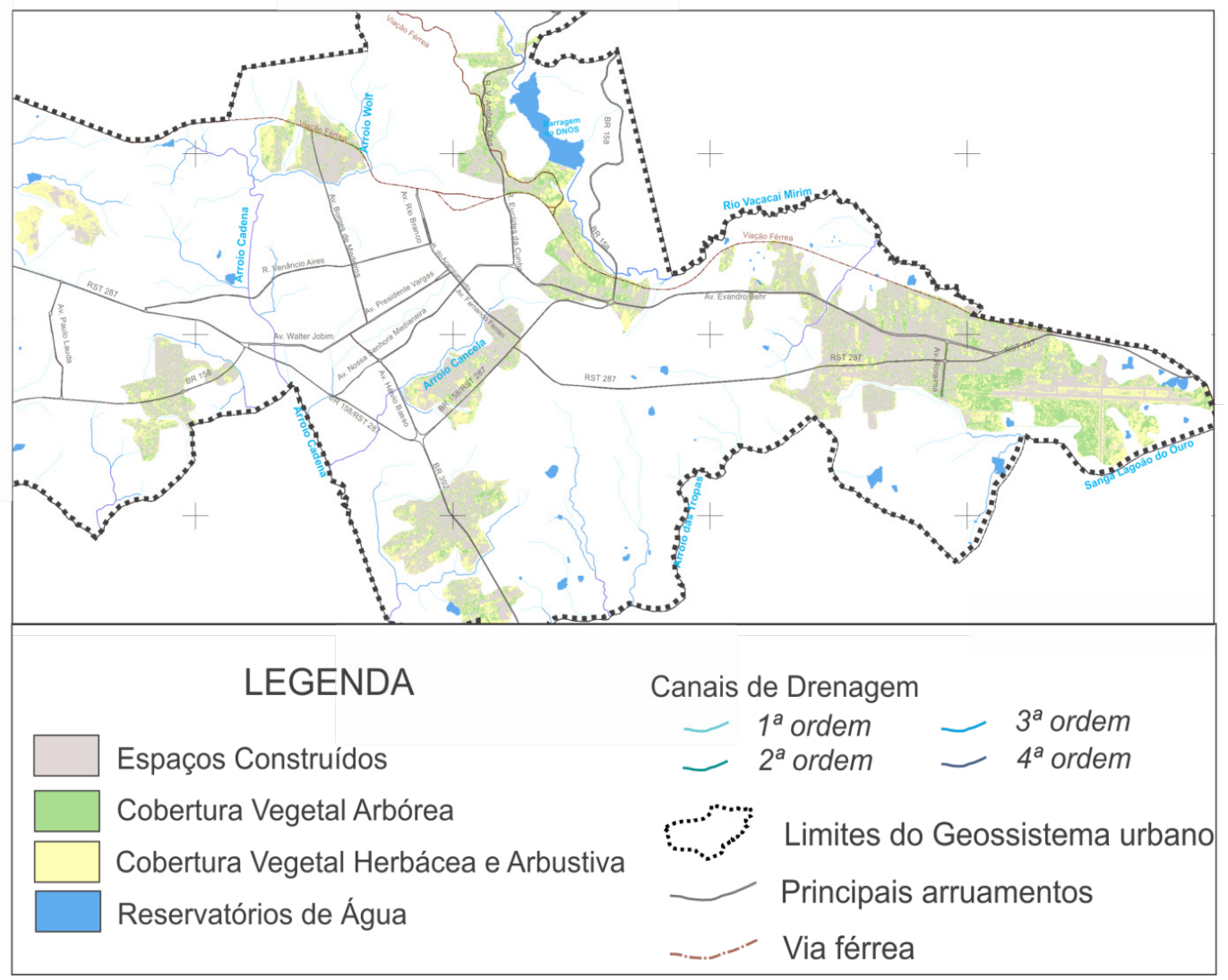

Fonte: elaborado pelos autores.

A Geofácie de áreas rururbanas (Figura13) corresponde às áreas de pouco avanço das edificações, onde ainda predominam os campos, em áreas de transição com a zona rural do município. O conjunto arbóreo se apresenta configurado predominantemente de forma isolada, apresentando algumas áreas em que a vegetação se demonstra agregada (áreas suburbanas no extremo oeste, centro-leste e leste).

Nestas condições, a classe de cobertura vegetal herbácea e arbustiva é a que n.3, p. 209-228, set./dez. 2013

Análise da configuração dos fragmentos de cobertura vegetal com base na definição de unidades de paisagem na área urbana de Santa Maria (RS) ocupa aproximadamente 58\% do total da Geofácie, estando outros 24\% associados à cobertura vegetal de porte arbóreo. O pouco avanço das áreas edificadas é expresso no fato de que apenas $17,36 \%$ da área dessa Geofácie está associado à classe de espaços construídos. 
Uma política adequada de resgate da qualidade ambiental urbana da cidade poderia criar medidas especiais de valorização destas áreas, planejando os jardins, pomares e hortas como "reservatórios de biodiversidade" que, graças à sua distribuição radial ao redor do centro mais edificado, poderiam servir como apoio e refúgio às espécies que transitam pelos espaços livres da área central da cidade. Além disso, a preservação das atuais estruturas ecológicas dessa unidade de paisagem também cumpre um especial papel na regulação hidrológica do sistema, especialmente nas áreas mais baixas e de menor declividade, onde as áreas livres servem como amortecedores da água escoada pela chuva em episódios de precipitação pluviométrica mais intensa.

Figura 13 - Uso e cobertura da terra na Geofácie de áreas rururbanas, revelando a distribuição de cobertura vegetal da área.

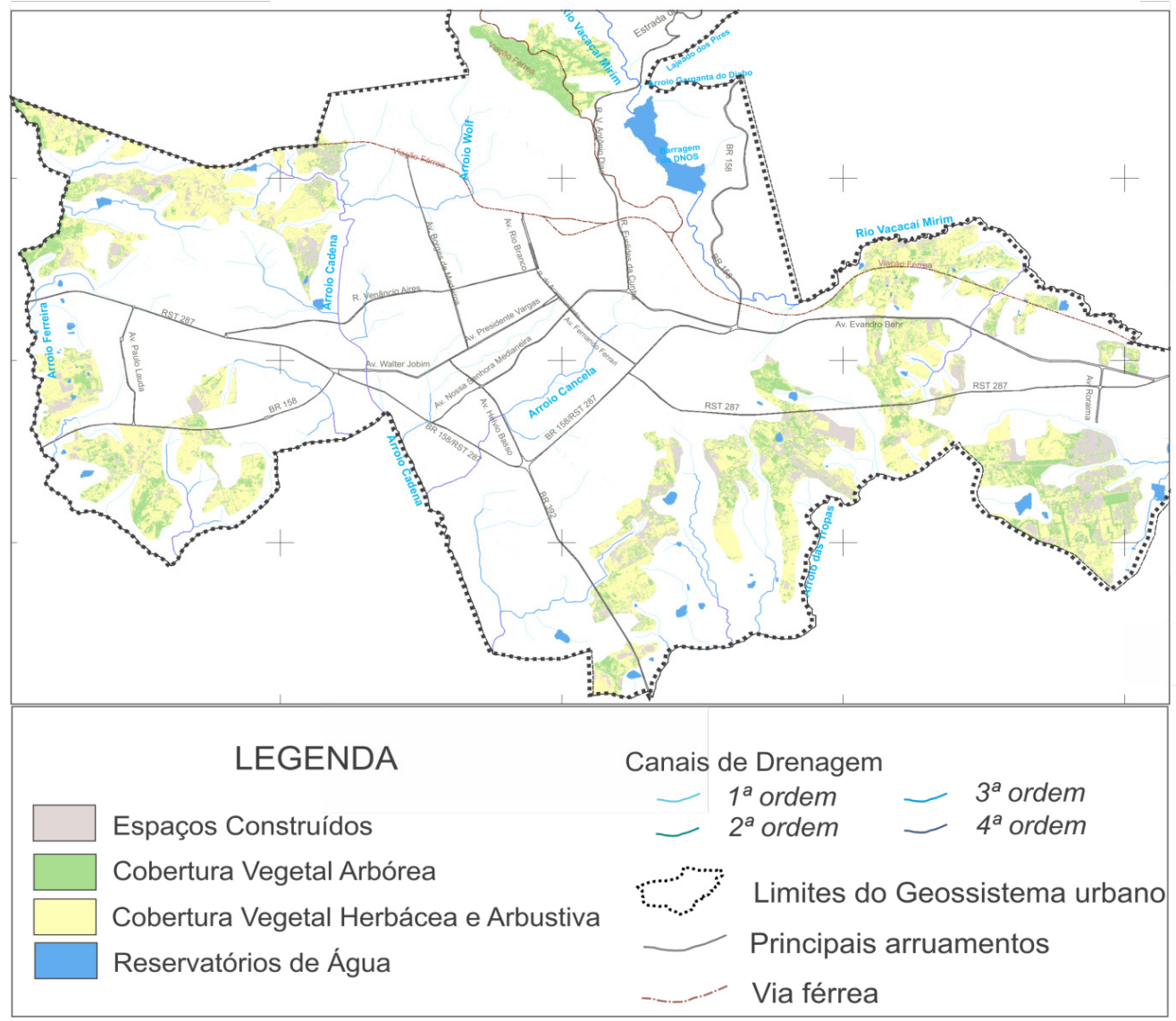

Fonte: elaborado pelos autores.

\section{Considerações finais}

A partir dos resultados obtidos, observa-se que a distinção de unidades de paisagem dentro da área urbana de Santa Maria para a análise da configuração dos fragmentos de cobertura vegetal demonstrou-se como uma boa estratégia para a obtenção de informações quantitativas mais contextualizadas e que melhor explicam a situação da distribuição de cobertura vegetal na cidade. Revela-se que mesmo com uma porcentagem de cobertura vegetal arbórea de cerca de 33\%, a paisagem urbana de Santa Maria apresenta áreas com altos níveis de isolamento dos fragmentos de cobertura vegetal, como observado na Geofácie de áreas densamente edificadas, sendo que a porcentagem encontrada para toda a área urbana é baseada muito em função dos grandes fragmentos existentes na Geofácie de morros do rebordo, na zona norte da cidade, e na Geofácie de morros testemunhos, na zona centro-leste.

Geografia Ensino \& Pesquisa, v. 17, n.3, p. 209-228, maio/ago. 2013.

Alves, D. B.; Figueiró, A. S. 
Embora seja bastante evidente que a inserção da cobertura vegetal pode contribuir com a gestão ambiental urbana das cidades, é importante destacar que aqui não se defende que as políticas ambientais urbanas devam ser reduzidas apenas a esse tipo de ação. É extremamente importante que sejam melhor considerados demais atributos como a proteção e controle de qualidade dos recursos hídricos, a manutenção e limitações de uso de acordo com as condições geomorfológicas (tais como os problemas relacionados a ocupação de encostas), entre outro fatores.

Não há dúvidas de que o estudo da qualidade ambiental urbana envolve uma complexidade de elementos interatuantes, onde, todavia, a vegetação desempenha um papel bastante importante. Ainda assim, em função desta complexidade de forças, a pressão urbana sobre a paisagem natural na qual se expande e transforma, com os seus diferentes aspectos e sujeitos, pode resultar em padrões de degradação dificeis de serem interpretados fora do contexto sistêmico da paisagem em que se inserem (MURCIA, 1995). Para além de um estudo de caso, esta tentativa de compreensão sistêmica da paisagem é, por certo, a melhor contribuição que este trabalho pode oferecer, embora represente ainda um processo incompleto e insuficiente para orientar uma reordenação mais profunda da arquitetura da paisagem na cidade de Santa Maria.

Acredita-se que os diferentes campos de pesquisa em Geografia, que desenvolvem suas investigações relacionadas ao crescimento urbano, podem melhor explorar a questão das intensidades de uso antrópico e seus padrões de uso e ocupação, com a finalidade de contribuir de forma ampla e plena com o planejamento das cidades. Nesse sentido, o diálogo entre as concepções teórico-metodológicas desenvolvidas pela Geografia Física e pela Ecologia Urbana podem render bons debates para melhor compreender a dinâmica espacial e temporal urbana.

\section{Agradecimentos}

Os autores agradecem ao Conselho Nacional de Desenvolvimento Científico e Tecnológico (CNPq), pela bolsa de mestrado $\mathrm{CNPq}$ concedida ao primeiro autor para o desenvolvimento da pesquisa que subsidiou a elaboração deste trabalho.

\section{Referências}

ALBERTI, M. The effects of urban patterns on ecosystem function. International Regional Science Review. Sage Publications, v.28, n.2, 2005. p.168-192. Disponível em: <http://irx.sagepub.com/ content/28/2/168.abstract>. Acesso em 21 de jun. de 2011.

ALBERTI, M.; MARZLUFF, J. M. Ecological resilience in urban ecosystems: Linking urban patterns to human and ecological functions. Urban Ecossystems. Kluwer Academic Publishers, n. 7, 2004, p. 241-265. Disponível em: <http://www.springerlink.com/content/w2k2705776j6t84n/>. Acesso em 21 de jun. de 2011.

ALVES, D. B. Cobertura vegetal e qualidade ambiental na paisagem urbana de Santa Maria (RS). Dissertação (Mestrado em Geografia). Programa de Pós Graduação em Geografia, Universidade Federal de Santa Maria. Santa Maria, 2012.

BEROUTCHACHVILI, N.; MATHIEU, J.L. L'étologie des géosystèmes. L’Espace Géographique, Paris, v. VI, n. 2, p. 73-84, 1977.

Geografia Ensino \& Pesquisa, v. 17, n.3, p. 209-228, set./dez. 2013

Análise da configuração dos fragmentos de cobertura vegetal com base na definição de unidades de paisagem na área urbana de Santa Maria (RS)
BERRY, B.J.L; HORTON, F.E. Urban environmental management. Englewood Cliffs: Prentice-Hall, 1974.

BERTRAND, G. Paisagem e geografia física global: esboço metodológico. Cadernos de ciências da terra. São Paulo, v. 13, p. 1-27, 1972.

CHRistofoletTi, A. Modelagem de Sistemas Ambientais. Edgard Blücher Ltda: São Paulo, 1999. 
DANSEREAU, P. As dimensões ecológicas do espaço urbano. In: VIEIRA, P. F.; RIBEIRO, M. A.

Ecologia humana, ética e educação: A mensagem de Pierre Dansereau. Porto Alegre: Pallotti, 1999.

DIAS, G. F. Elementos de ecologia urbana e sua estrutura ecossistêmica. Brasília: IBAMA, 1997.

ESCOBEDO, F. J.; NOWAK, D. J.; WAGNER, J. E. MAZA, C. L. de la; RODRIGUEZ, M. CRANE, D. E.; HERNANDEZ, J. The socioeconomics and management of Santiago de Chile's public urban forests. Urban Forestry \& Urban Greening. Elsevier GmbH, v. 4, abril/2006, p.105-114. Disponível em: <http://www.sciencedirect.com/science/article/pii/S1618866705000543>. Acesso em 21 jun. 2011.

FIGUEIRÓ, A. S. Tradição e mudança em Geografia Física: apontamentos para um diálogo interno. In: FIGUEIRÓ, A. S.; FOLETO, E. M. Diálogos na Geografia Física. Santa Maria: Ed. da UFSM, 2011.

FORMAN, R. T. T. Land mosaics: the ecology of landscapes and regions. Cambridge: Cambridge Press, 1995.

GARCIA-ROMERO, A.; JIMÉNEZ, J. M. El paisaje en el ámbito de la Geografía. México: Ed. da UNAM, 2002.

GRIMM, N. B.; GROVE, J. M.; PICKETT, S. T. A.; REDMAN, C. L. Integrated approaches to longterm studies of urban ecological systems. BioScience. v. 50, n. 7, jul./2000. p.571-584. Disponível em: <http://schoolofsustainability.asu.edu/docs//papers/2000/Grimm_et_al_2000.pdf > Acesso em 21 de junho de 2011.

IBGE - INSTITUTO BRASILEIRO DE GEOGRAFIA E ESTATÍSTICA. Censo demográfico de 2010. Brasília, 2010.

JIM, C. Y. Tree-canopy characteristics and urban development in Hong Kong. Geographical Review, v. 79, n. 2, abr. 1989 , p. 210-225.

LAURIE, I. C. Nature in cities. Chichester: Wiley, 1979.

MADUREIRA, H.; ANDRESEN, T.; MONTEIRO, A. Green estructure and planning evolution in Porto. Urban Forestry \& Urban Greening. . Elsevier GmbH, v. 10, fev/2011, p.141-149. Disponível em: <http://www.sciencedirect.com/science/article/pii/S1618866711000033>. Acesso em 21 jun. 2011.

MARCHIORI, J. N. A vegetação em Santa Maria. Ciência \& Ambiente, Santa Maria, n. 38, p.93-112, jan./jun. 2009.

MASCARÓ, L. Vegetação Urbana. 2a ed. Porto Alegre: Mais Quatro. 2005. 204p.

MONTEIRO, C. A. de F. Geossistemas: a história de uma procura. São Paulo, Contexto, 2000.

MURCIA, C. Edge effects in fragmented forests: implications for conservation. Tree, v. 10, n. 2, p. 5862, 1995.

NASCIMENTO, D. B.; FOLETO, E. M. A Reserva da Biosfera da Mata Atlântica como referência na instituição e zoneamento da Área de Proteção Ambiental do Vacacaí-Mirim/RS. In: FIGUEIREDO, L. C.; FIGUEIRÓ, A. S. Geografia do Rio Grande do Sul: temas em debate. Santa Maria: Ed. da Universidade Federal de Santa Maria, 2010.

PICKETT, S. T. A.; CADENASSO, M. L.; GROVE, J. M.; NILON, C. H.; POUYAT, R. V.;

ZIPPERER, W. C.; COSTANZA, R. Urban ecological systems: linking terrestrial ecological, physical, and socioeconomic components of metropolitan areas. Annual Review of Ecology and Systematics, vol. 32, 2001, p. 127-157.

RODRIGUES, C. A teoria geossistêmica e sua contribuição aos estudos geográficos e ambientais.

Revista do Departamento de Geografia USP. São Paulo, n.14, p. 69-77, 2001.

RODRIGUES, J. M. M; SILVA, E. V. da; CAVALCANTI, A. P. B. C. Geoecologia das paisagens: uma visão geossistêmica da análise ambiental. $3^{\mathrm{a} e d . ~ F o r t a l e z a: ~ E d i t o r a ~ d a ~ U F C, ~} 2010$.

Geografia Ensino \& Pesquisa, v. 17, n.3, p. 209-228, maio/ago. 2013.

ROSS, J. L. S. Geografia do Brasil. São Paulo: EDUSP, 2001.

Alves, D. B.; Figueiró, A. S.

ROUGERIE, G.; BEROUTCHACHVILI, N. Gèosystèmes et paysages: bilan et méthodes. Paris: Armand Colin, 1991. 
TIAN, Y.; JIM, C.Y.; TAO, Y.; SHI, T. Landscape ecological assessment of green space fragmentation in Hong Kong. Urban Forestry \& Urban Greening. Elsevier GmbH, v. 10, fev./2011, p.79-86.

Disponível em: < http://www.sciencedirect.com/science/article/pii/S1618866710000804>. Acesso em 21 jun. 2011.

TURNER, M.; O’NEILL, R.V.; GARDNER, R. H.; MILNE, B.T. Effects of changing spatial scale on the analysis of landscape pattern. Landscape Ecology, v. 3, n. 3/4, p. 153-162, 1989.

YOUNG, R. F. Managing municipal green space for ecosystem services. Urban Forestry \& Urban

Greening. Elsevier GmbH, v. 9, set.2010, p.313-321.Disponível em: < http://www.sciencedirect.com/ science/article/pii/S1618866710000543>. Acesso em 21 jun. 2011.

\section{Correspondência:}

Daniel Borini Alves - Universidad de Zaragoza (UNIZAR), Facultad de Filosofia y Letras, Departamento de Geografía y Ordenación del Territorio. Calle Pedro Cerbuna, 12, 50009, Zaragoza Espanha.

E-mail: danielborini.geo@gmail.com

Recebido em 14 de junho de 2013.

Revisado pelo autor em 20 de dezembro de 2013.

Aceito para publicação em 23 de dezembro de 2013. 